\title{
Applications of Non-destructive Tests for Diagnosis of Heritage Buildings: Case Studies from Singapore and Malaysia
}

\author{
Chung Wan Wong
}

MAEK Consulting Pte Ltd, Singapore

Email:wongcw@maek.com.sg

\begin{abstract}
Non-destructive tests have been increasingly used in historic buildings not only for pre-restoration investigation but also as useful tools to evaluate the effectiveness of eventual interventions. These tests can complement and supplement destructive tests like laboratory analysis of extracted samples as long as a sound sampling plan has been put in place to commensurate with the pattern and extent of dilapidation and materials distribution. Common methods employed in projects in Singapore and Malaysia include the infrared thermography, ground penetrating radar, microwave moisture tomography and ultrasonic pulse echo tomography. The paper discusses about a selection of case studies, demonstrating the application of various techniques for the identification of hidden details, defects and deterioration, and moisture detection.
\end{abstract}

KEYWORDS non-destructive tests, infrared thermography, radar, ultrasonic pulse echo, microwave

Received December 27, 2018; accepted February 3, 2019.

\section{Introduction}

The use of non-destructive tests for diagnosis of heritage buildings in Singapore has been gaining traction albeit slowly. Their applications in the past have been largely confined to new constructions and recent buildings as part of quality control and investigation of construction failures. The slow adoption of such techniques for historic buildings is due primarily to the difficulty in interpretation of the signals or results obtained from the tests especially for complex heritage buildings which often comprised of a multitude of composite materials. However, such tools are even more beneficial for historic buildings because more often than not, there is a considerable lacking of information on their construction details and materials. Before any restoration works can be carried out on a heritage building, it is imperative that adequate investigation and survey be carried out to better understand not only its historical construction details and materials, but also the conditions and extent of dilapidation. The same tools can subsequently be employed to assess the efficacy of interventions (Svahn 2006; McCann and Forde 2001; Binda and Saisi 2009).

Being non-destructive, these techniques can practically be engaged extensively over larger areas as compared to destructive methods. Nevertheless, intrusive inspection like breakouts is often necessary to verify the findings from and supplement the non-destructive tests though the extent of damages can be minimised by limiting the size of breakouts or through the use of borescope and video-probe. Laboratory analyses of extracted samples like mortar, bricks and timber are also inevitable as most chemical, physical and mechanical properties cannot be determined from the nondestructive tests. The findings from the non-destructive methods can guide in the selection of strategic sampling points for the more destructive activities. Careful planning and thorough considerations will, therefore, need to be given to select appropriate samples, with a minimal but yet adequate amount to provide reliable results in accordance with the various analyses and purposes.

In their applications, attention should be paid to locations with different symptoms, building orientation where visual defects are found, distribution and extent of the defects, and condition of weather exposure. Hence, visual inspection and recognition of the pattern of dilapidation and construction is perhaps the most important non-destructive technique in the diagnosis of heritage buildings. Meticulous planning is essential to maximising the use of the non-destructive tests to demonstrate their full potential. 
The common techniques which the authors have successfully and regularly employed in the diagnosis of historic buildings in Singapore and Malaysia include the infrared thermography, ground (surface) penetrating radar, microwave moisture tomography and pulse echo tomography.

\section{Infrared Thermography}

Infrared thermography is based on the principle that any features or anomalies below and around the surface finishing affect or change the rate at which heat flow through the structure. These features could be due to singly or a combination of sub-surface voids, delamination, poor bonding, water/ moisture retention, deteriorated surface, different materials, materials of different porosity or thermal heat transmission and air leakages. The changes in the heat flow can cause localised differences in surface temperature. Thus, by measuring surface temperature under conditions of heat flow, subsurface or non-visible surface features can be located.

The values of temperature indicated on the thermograms are typically regarded as 'apparent temperatures'. A relatively high differential heat transfer between the mediums (i.e., paints, moisture, trapped air, plaster, etc.) needs to exist for the anomalies to be detected. This is challenging in tropical climatic conditions where the daily ambient temperature variation is small. The difficulties were overcome by timing the infrared thermographic inspection to catch the moment when the contrast in the surface temperature is most apparent. Such moments include in the morning during the initial period of sunrise when the building is being heated up, in the evening after sunset when the building cools down, or after a rain when the building is drying up. Occasionally the heat flow or surface thermal variation was induced by spraying the wall or ponding the roof with water, or by actively heating the surface (active infrared thermography).

The resulting surface temperature profiles can, however, be affected by many factors such as colour, surface roughness, types of surface (glazed or reflective) and the presence of surface contaminants. The distance and angle at which the images are captured, the presence of wind and cloud cover also affect the results. Shadings, blockages by trees and recessed corners had often hampered complete inspection of a building exterior. It can be difficult to detect any anomalies or hidden details beyond several centimetres from the surface with this method. Verification and confirmation of the findings from infrared thermography are usually required through tactile inspection or the use of supplementary inspection (Plesu, Teodoriu and Taranu 2012; Grinzato 2012).

\section{Microwave Moisture Tomography}

This technique involves emitting microwave energy to the surface of the materials via a microwave sensor head. Since water has a very high dielectric constant, the electric field generated by the microwave will result in the molecules of water trapped inside the materials to vibrate and rearrange (Svahn 2006). Spots with trapped moisture can thus be detected by the differences in the dielectric constant between the dry spots and those with moisture. Probes with varying depth of measurements had been employed to determine the moisture level at different depths. After all the readings are collected, the measurement points are mapped to generate a tomographical matrix showing the moisture distribution and locations of trapped moisture at varying depths. The author had regularly used this technique to check for rising damp, identify the source of water seepage or seepage paths and verify the effectiveness of moisture treatment. This method, however, may not necessary give true moisture readings of the substrate unless calibration has been carried out with the material under evaluation. In addition, frequently the measurements had been made across substrates comprising of different materials or different layers of materials, for instance, render and a mixture of bricks and mortar joints. The presence of metallic elements can also affect the readings though the presence of soluble salt does not influence the results. The ability of this method to investigate large sections of a wall non-destructively as compared to the conventional approach that requires drilling of powder for laboratory gravimetric testing is its biggest advantage. The use of the gravimetric method to measure the total moisture content is still unavoidable though it can be strategically targeted at the right spots and minimised. Moreover, drilled powder provides the additional advantage of being able to be used to determine the hygroscopic moisture content as part of the assessment of salt content in the walls.

\section{Ground (Surface) Penetrating Radar (GPR)}

GPR generally works on the principle of reflective energy. A handheld unit consists of a transmitting antenna and a receiving antenna for the energy. The transmitting antenna sends out a diverging beam of electromagnetic wave energy pulse in the range of $500 \mathrm{MHz}$ to $1 \mathrm{GHz}$ through the structure, and the receiving antenna receives the reflected energy pulse from materials of different dielectric properties. The electrical properties of the subsurface layers/materials influence the speed and attenuation of 

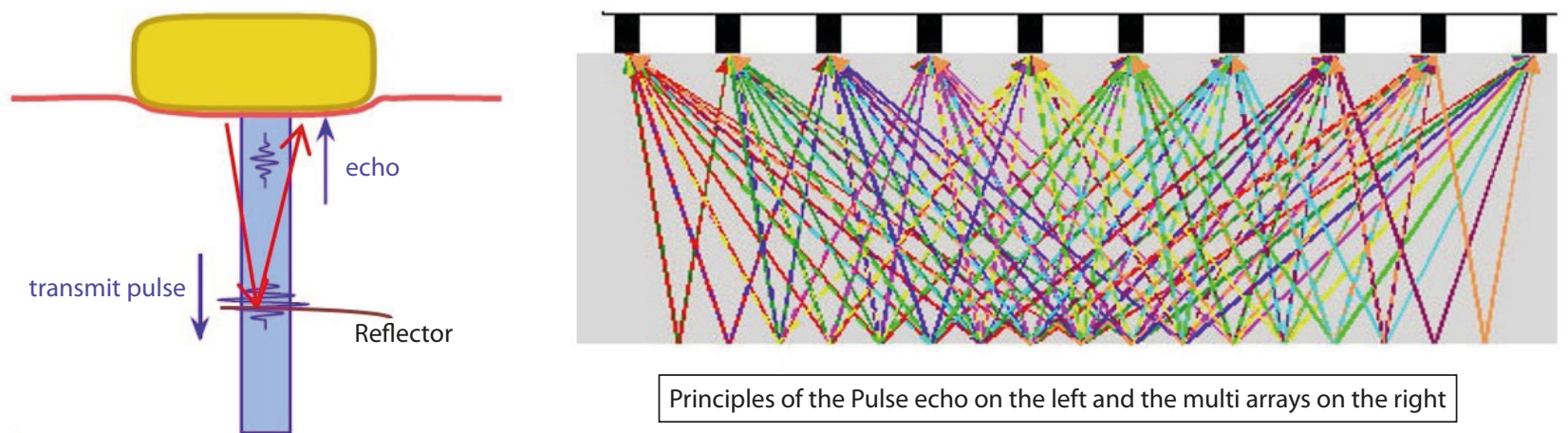

Principles of the Pulse echo on the left and the multi arrays on the right

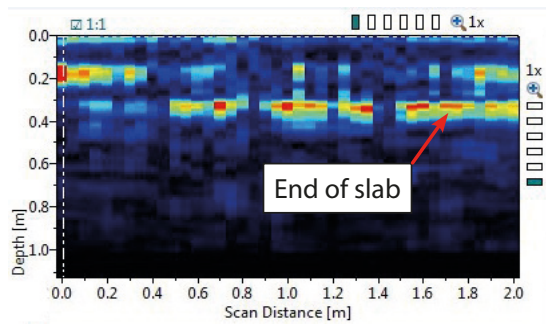

Figure 1 Principles of Pulse Echo and typical tomograms showing the end of a floor and the presence of cavity (Source: the author).

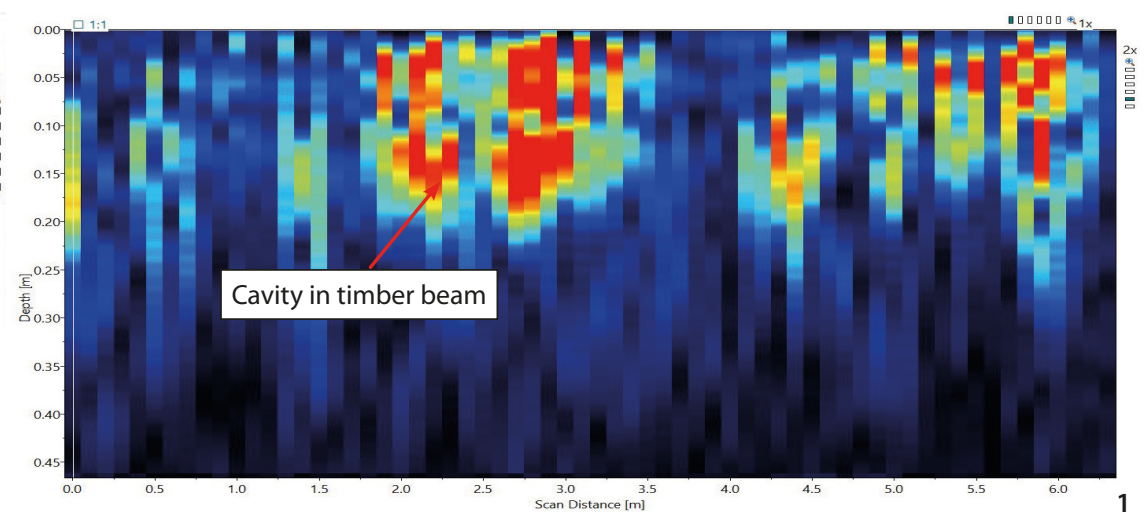

the signal. For instance, the electrical permittivity determines the signal velocity whereas the electrical conductivity affects signal attenuation. Signals returning to the surface antenna are analysed to determine depth or pattern of reinforcement or any embedment below ground or in the concrete, construction details of the slabs and masonry wall, identify the presence of cavities, trapped moisture and embedded services (Concrete Society 1997; Maierhofer, Ziebolz and Kopp 2003; Maierhofer, Borchardt and Henschen 1995; Ranalli, Scozzafava and Tallini 2004; Himi et al. 2016). However, interpretation of the signals or radargram requires highly skilled and experienced engineers. Verification of the interpretation with other methods is inevitable.

In a medium with high dielectric constant, attenuation of the electromagnetic energy results in poor quality signals. This can occur if the medium has high moisture content or contain clay or salt. On the other hand, the presence of attenuated signals can be used to identify the presence of salt deep within a wall. Embedded metallic objects for instance heavily congested steel reinforcement in concrete will also give poor signals as most of the energy is reflected. Any features below the congested bars will not be easily detected. Nonetheless, this technique is one of the most beneficial tools to uncover hidden construction details of old buildings in which drawings are not available. Three-dimensional scanning can be employed to provide the mapping of a large area with good depth resolution with the aid of third-party software such as GPR Slice. Successful applications include uncovering details such as wall thickness, different layers, embedded objects, the presence of cavities, trapped moisture and zones with salts within masonry walls.

\section{Pulse Echo Tomography}

This technique is based on the detection and analysis of reflected ultrasonic pulse through dry contact transducers. Shear waves were employed for their easier spread and deeper penetration into the material. With the use of several bundled transducers, the multiple reflections are coherently accumulated and analysed by 'Synthetic Aperture Focusing Technique' to build 3D images and $2 \mathrm{D}$ cross-sections of the internal of the material. This technique is used to generate images to show internal disturbances that are not visible at the surface such as voids, cracks, honeycombing, the thickness of members, embedded structures etc. (Krause, Dackermann and Li 2015; Dackermann et al. 2014; Michaux and Grill 2011). This method is not affected by the electrical properties of the medium unlike GPR but will not be able to detect moisture. Whilst this technique had mainly been employed for investigation of concrete structures with good results, 

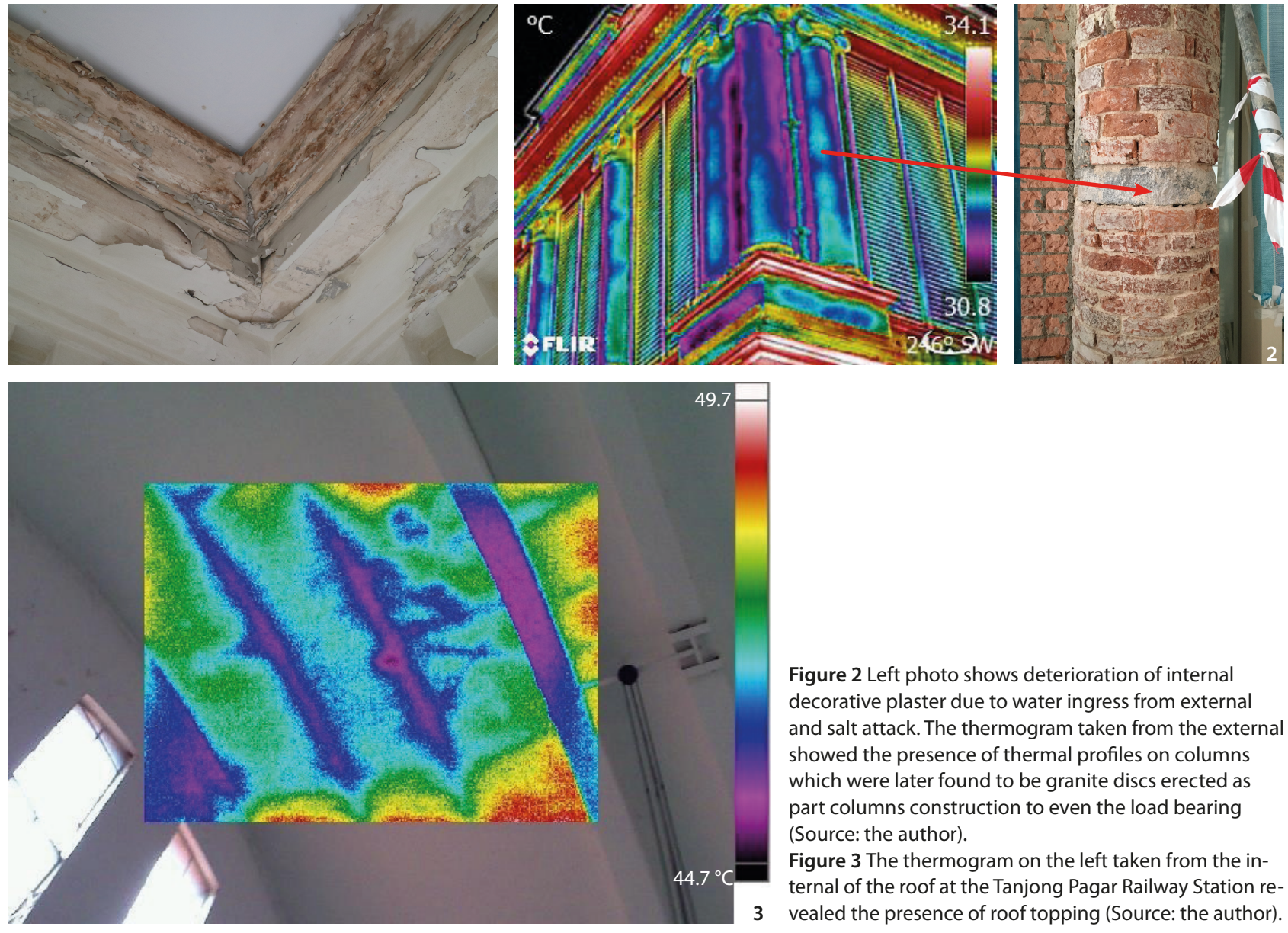

Figure 2 Left photo shows deterioration of internal decorative plaster due to water ingress from external and salt attack. The thermogram taken from the external showed the presence of thermal profiles on columns which were later found to be granite discs erected as part columns construction to even the load bearing (Source: the author).

Figure 3 The thermogram on the left taken from the internal of the roof at the Tanjong Pagar Railway Station revealed the presence of roof topping (Source: the author).

its application for masonry construction has been fraught with difficulties due to the largely heterogeneity of such construction arising from the interfaces of masonry units and mortar joints. Such interfaces had resulted in multiple echoes which had masked other features of interests such as void and embedded objects. Recent trials however on structural timber members revealed that this technique can be used to check for rot and termite attack (Figure 1).

\section{Identification of Hidden Construction Details}

In one of the mid- $19^{\text {th }}$-century building constructed of masonry load bearing members, salt attack and water seepage have resulted in deterioration of the internal decorative cornices and ionic column capitals. From the infrared thermographic inspection on the external façade, regular thermal patterns could be seen on the circular columns, which were subsequently found to be circular granite discs installed at regular intervals along the height of the columns (Figure 2). This is because the granite discs have lower thermal heat capacity and tend to absorb heat better than the clay brick units. This thus resulted in the render around the granite disc appearing cooler during the solar heating stage (morning) as the granite discs absorb the heat. The discs were later uncovered to have been traditionally laid to allow even bearing of the load in the columns.

At the Tanjong Pagar Railway Station which was constructed in the early $20^{\text {th }}$ century, the infrared thermographic survey revealed the presence of regular thermal patterns (cold strips) on the thin shell vault roof as recorded from internally (Figure 3). Due to their regular features, these are not thought to be typical of subsurface defects. Rather, the fact that they appeared as cold spots taken during hot days suggests the outline of rooftopping, possibly with irregular insulation properties. The areas with better insulation such as air void could have prevented heat flow through the roof thus appearing as colder spots from internally. Invariably verification via tactile inspection is necessary.

Within this Station, there are six (6 sets) triptychs panels in terracotta tiles from Doulton Company of UK (nowadays known as Royal Doulton), which were handpainted mural panels. Doulton's were the most successful of the architectural ceramic exporters in the early $20^{\text {th }}$ 

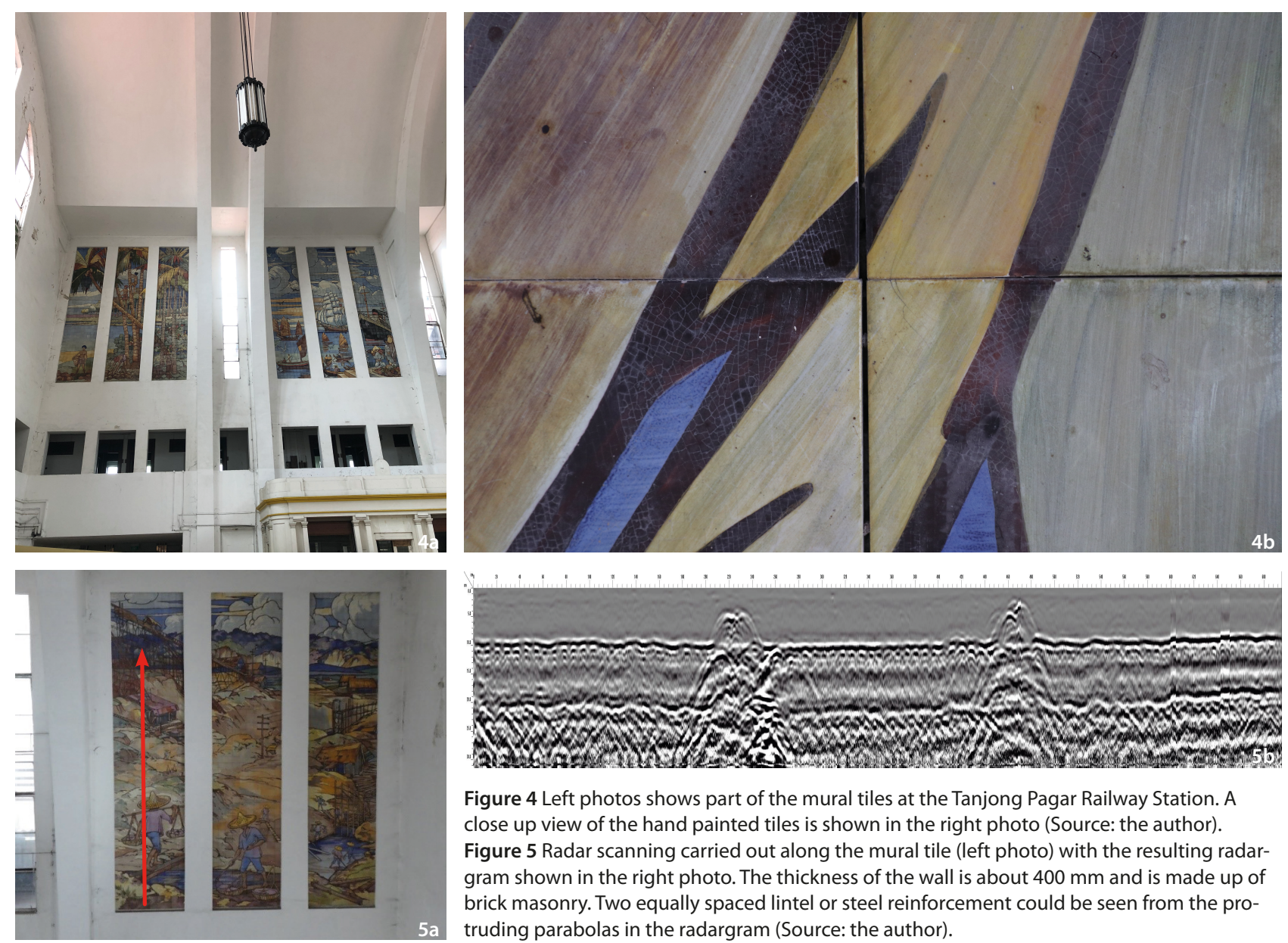

Figure 4 Left photos shows part of the mural tiles at the Tanjong Pagar Railway Station. A close up view of the hand painted tiles is shown in the right photo (Source: the author). Figure 5 Radar scanning carried out along the mural tile (left photo) with the resulting radargram shown in the right photo. The thickness of the wall is about $400 \mathrm{~mm}$ and is made up of brick masonry. Two equally spaced lintel or steel reinforcement could be seen from the protruding parabolas in the radargram (Source: the author).

century. Apart from their substantial terracotta trade, their largest ever tile contract, for around 7,500 tiles in 1935, was for the Keppel Road Railway Station in Singapore (completed in 1932). These comprised of 18 hand-painted pictorial tile panels designed by William Rowe, each about 23 feet high by 5 feet wide, showing local primary industries such as rubber, rice, tin mining and copra. The panels were arranged in groups of three along two walls of the booking hall (Figure 4).

As the mural tiles are showing signs of cracks, crazes and debonding, there was a need to establish the construction of the walls on which the tiles were laid. In the absence of as-built drawings for the non-load bearing walls, radar was used. The scan revealed that the tiles were installed onto $\sim 400 \mathrm{~mm}$ thick brick walls with intermediate beams/lintels equally spaced over the height of the walls (Figure 5), and flanked by concrete beams at the top and columns in between each panel of mural tiles. These are important findings in assessing the stability of the infill walls and hence the invaluable mural tiles.

Over in Malaysia, as part of the restoration of the National Mosque in Kuala Lumpur required an investigation into the locations of embedded services and pipes in particularly metal rainwater pipes. The pipes were apparently embedded within the concrete structures, but there is no record as to the locations and layout. Through the use of GPR scanning, the locations of the pipes were found embedded in some of the concrete columns and slabs. These are clearly evident from the presence of parabolas in the resulting radargrams (Figure 6). In fact, the parabolas appeared in pairs suggesting that there are two pipes at each location. The pipes appeared approximately in the mid-thickness of the slab as the bottom layer of steel reinforcement bars could be easily discerned. The marble tiling layers cause the presence of multiple echoes at the top of the slab.

The above case studies showed that both infrared thermography and radar could be used to detect hidden details. Infrared depends on heat flow and works best on external or on areas with active heat flow. Its efficacy is governed by weather and may not work well indoor where active heat flow is obscured. Radar, on the other hand, relies on the dielectric properties of the sub-layers and works best for detecting metals. Congestions of metal or the poorly differentiated dielectric constant of matrix 

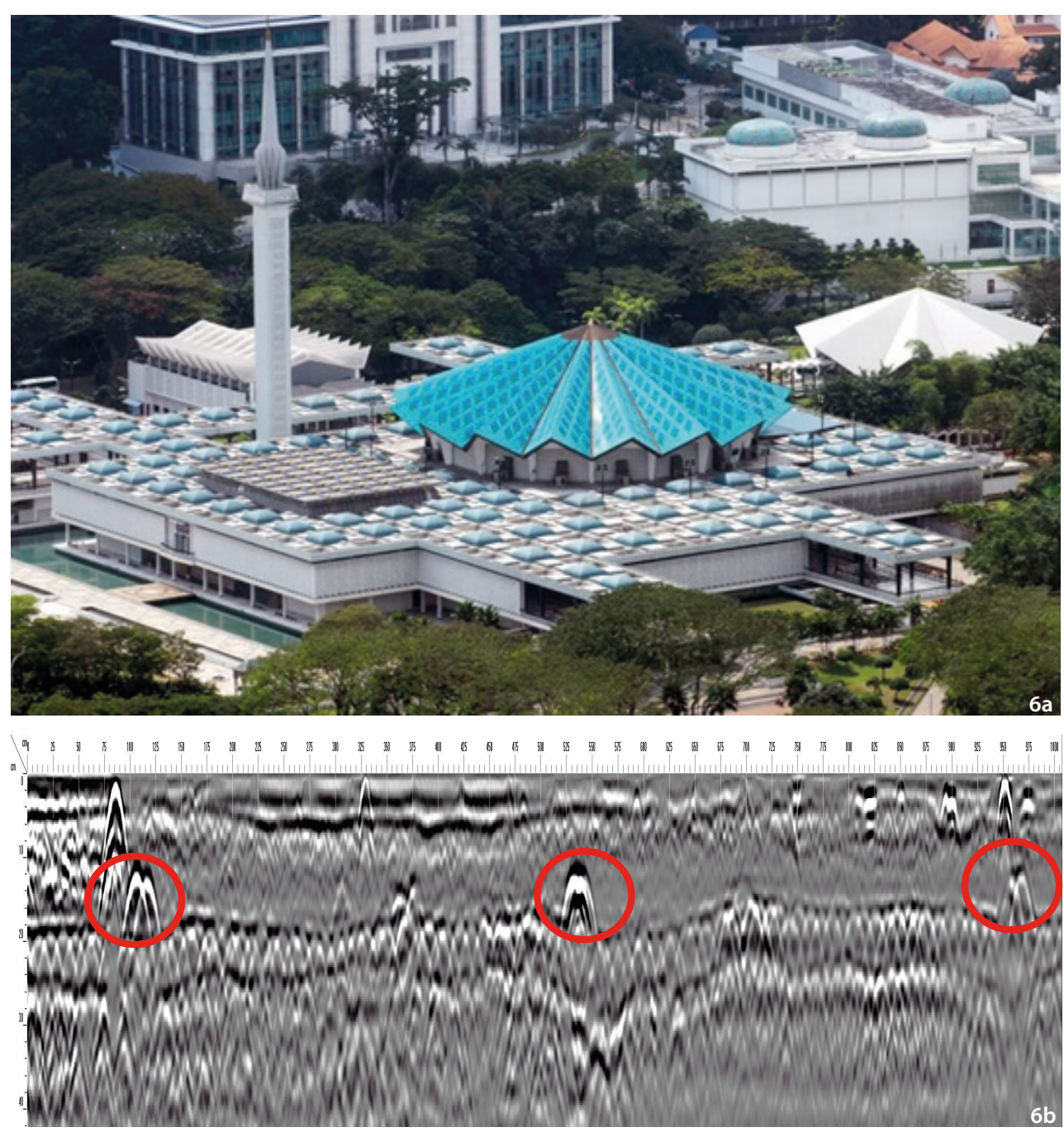

Figure 6 The radargram below revealed the locations of embedded rainwater pipes within the floor slab at the National Mosque in Kuala Lumpur, Malaysia (Source: the author).

and objects can make detection extremely difficult. Both techniques, however, need to be supplemented by other methods, which include breakout inspection. As can be seen from the cases presented, the cause of the thermal anomalies can only be established after breakout inspection. Radar meanwhile can only be carried out from close up but infrared scanning can be made from afar. Whilst the radar can detect the presence of object of different dielectric property, the actual material and dimension cannot be determined.

\section{Moisture Detection}

The St. George's Church along Minden Road in Singapore, constructed between 1910 and 1913, comprised largely of fair-faced clay brick façade. Sign of a damp-proof course had been installed as seen from a layer of different coloured mortar on the external façade close to the internal floor level (Figure 7). From the infrared thermography, dampness on the external was found but confined largely to below a damp proofing layer indicating the effectiveness of the damp proof course. This appeared largely as cold spot when the survey was carried out in the morning. This is due to the high thermal heat capacity and evaporative cooling of moisture rendering the damp area as cooler spots. At localised areas, however, dampness could be detected above the damp proof layer indicating isolated breach of the layer (Figure 8). From here, targeted rising damp treatment was being carried out. Internally, localised moisture was also found on the roof and some of the timber rafter, again appearing as 'cold spots' (Figure 9). This would then allowed detailed further investigation of the condition of the timber for wet rot, which would otherwise have gone undetected.

In the 117 years old Church of the Nativity of the Blessed Virgin Mary, rising damp and salt attack was evident throughout the masonry walls and columns externally and internally. Due to frequent repainting and patching of the walls, the extent of rising damp and salt attack could not be ascertained visually. Only localised spots 

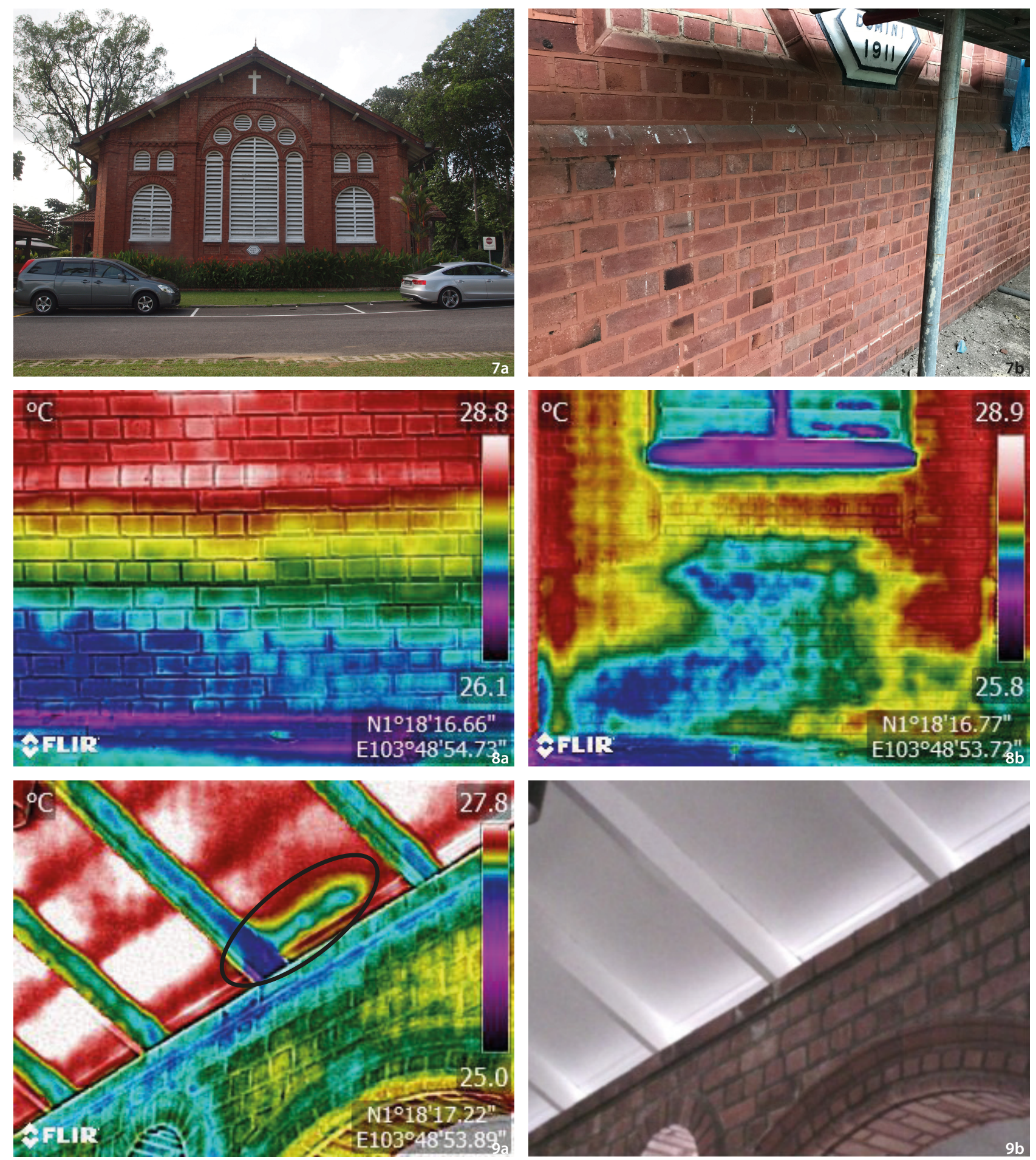

Figure 7 Fair faced brick façade of St. George's Church. A damp proof course could be seen near the foot of the wall as noted on the external façade in the right photo (Source: the author).

Figure 8 Dampness due to rising damp below the damp proofing layer is shown at the St George's Church as seen in the centre thermogram. The right thermogram indicates dampness above the damp proofing layer (Source: the author).

Figure 9 Trapped moisture in a timber rafter which could be potential for wet rot and seepage through the roof was detected through the presence of cold spots from the thermogram at St. George's Church (Source: the author).

of deteriorated and friable plaster accompanied by salt crystals could be seen (Figure 10). Even the use of infrared thermography was not able to identify the presence of rising damp due to the thick layers of paint that had obscured any potential thermal anomaly. In addition, the lack of heat source for the passive thermographic inspection especially when carried out internally failed to reveal any apparent temperature difference between the dry and 

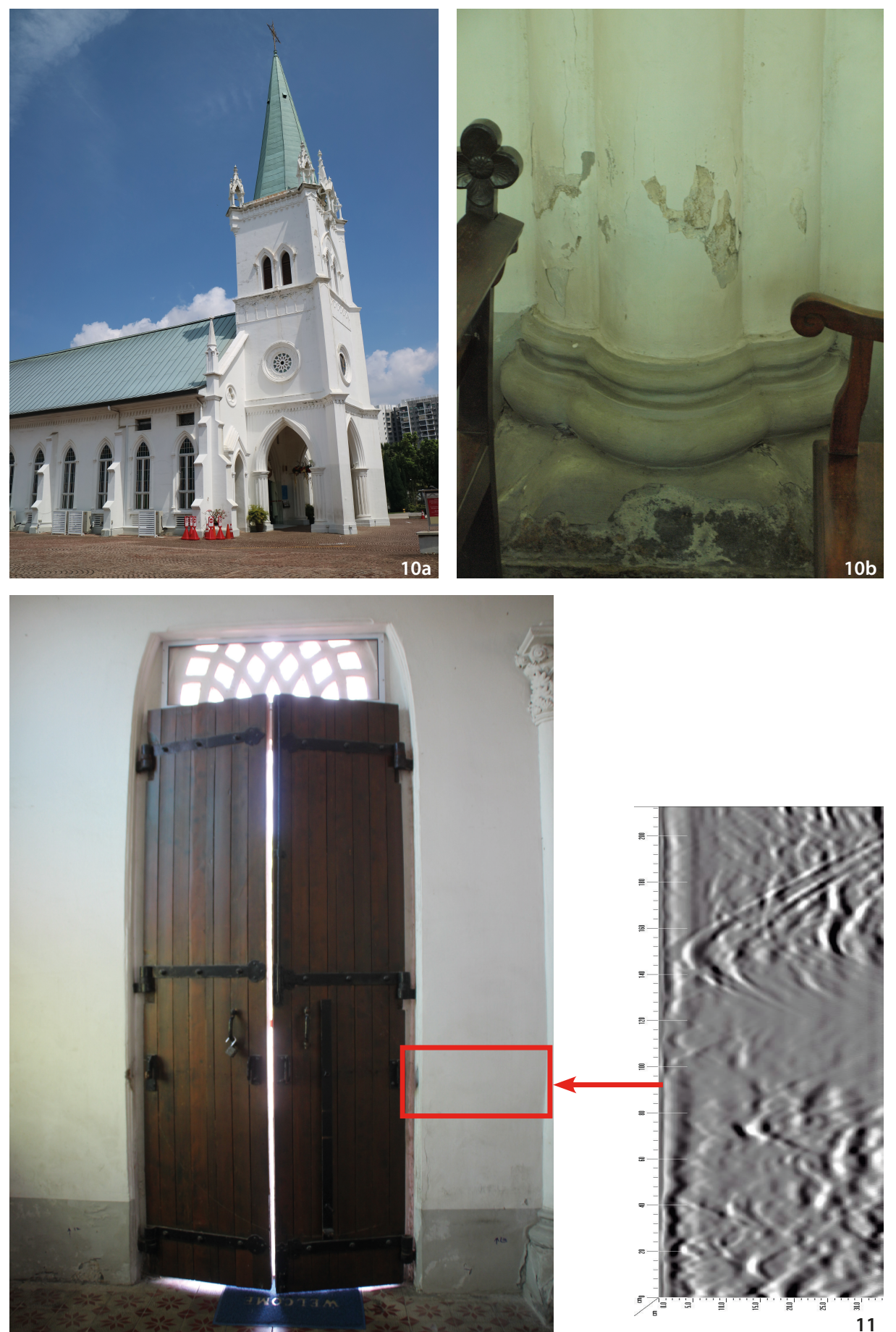

Figure 10 The left photo shows the Church of the Nativity of Blessed Virgin Mary. In the right photo, localised deterioration of the internal plaster around columns could be noted (Source: the author).

Figure 11 The radargram above exposed the zone with trapped salt within the wall at the Nativity of Virgin Blessed Mary identified from the attenuated electromagnetic signal despite the absence of visual symptom 11 (Source: the author).

damp wall. The use of moisture measurement meanwhile was fraught with uncertainty as the moisture level varied with the weather. The thick layers of film-forming paint have also altered the hygrothermal characteristic of the masonry wall due to the poor breathability of the paint. As a result, the height of rising damp and salt attack or zone of trapped salt within the wall had varied across the building. Through the use of GPR, zones with a higher salt concentration within the wall and hidden by the thick paint layers could be delineated despite the absence of a visible symptom. These appeared as severely attenuated electromagnetic signals due to the high dielectric constant of the soluble salt (Figure 11). These were subsequently verified with dust sampling and salt content analysis via ion chromatography. The salt was later identified to be made up predominantly of chloride.

The cases discussed above showed how infrared could be used to detect active moisture movement or entrapment in wall and timber. Where moisture is trapped deep within the wall and masked by thick layers of plaster and 

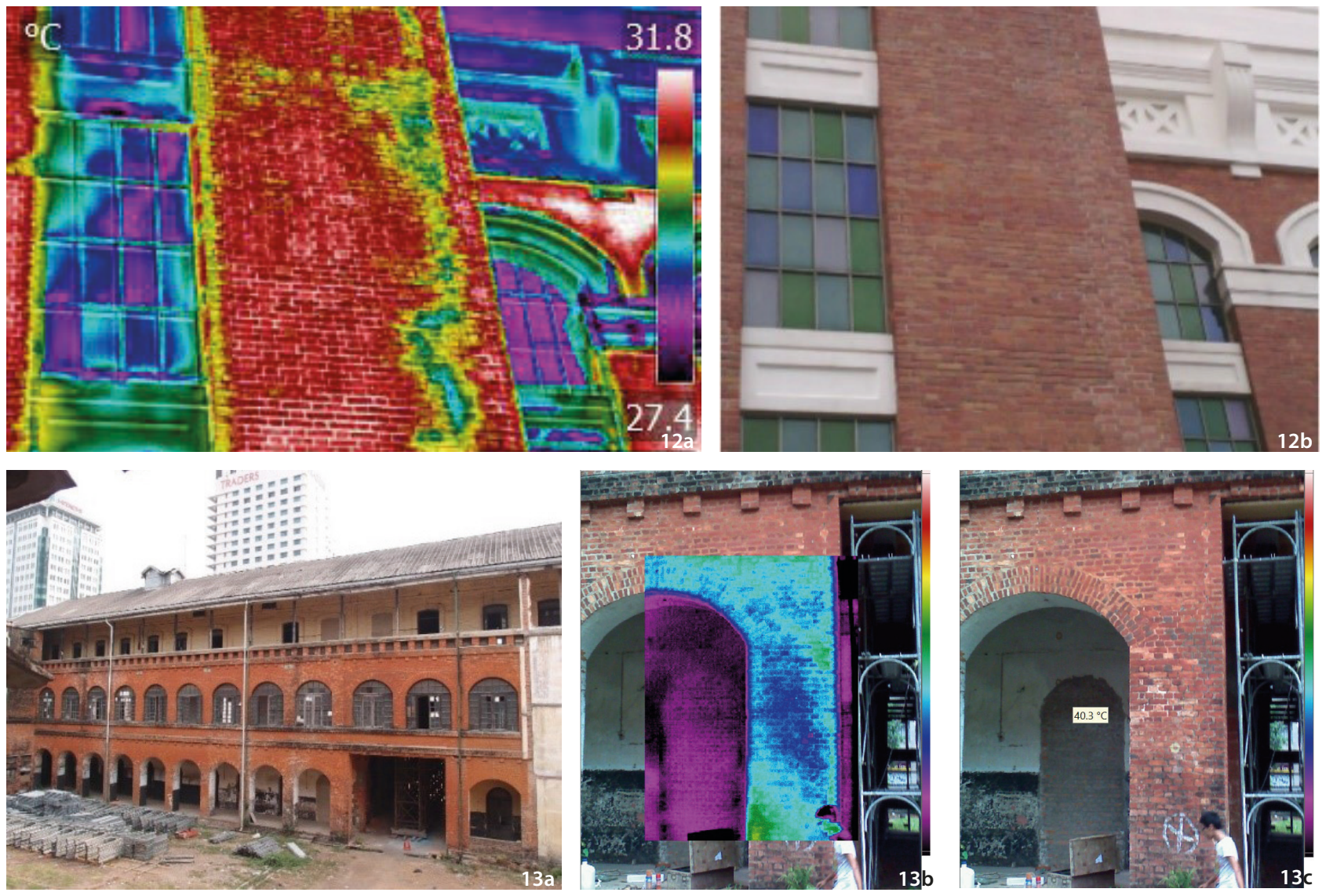

Figure 12 The presence of cracks could be highlighted from the infrared thermography at the St. James Power Station, taken after a short bout of rain. The ingress of water resulted in the crack line showing lower surface temperature (Source: the author).

Figure 13 The left photo shows the section of the Myanmar Railway Building. From the thermogram in the centre photo, deteriorated brickworks could be identified from the cold patches. The corresponding visual image is shown in the right photo (Source: the author).

paint, thermography is not effective. This shows that thermography is only able to detect anomaly within the surface layer of typically no more than several centimetres depth. The radar was found to be a good supplementary tool especially if there is soluble salt which increases the dielectric property of the substrate. Radar may not be as effective to merely detect the presence of moisture if the amount is low or there is little difference in the electrical property between a dry and wet substrate. Neither of the two methods can quantify the amount of moisture in the wall. Destructive gravimetric method is still unavoidable.

\section{Identification of Defects and Deterioration}

Identification of defects is one of the most common applications in most NDTs. The use of infrared thermography had helped to identify the presence and extent of cracks in the fair-faced brick façade at the St. James Power Station by inspecting a wet spell (Figure 12). These appeared as cold spots due to the higher thermal heat capacity of water which takes a longer time to heat up when exposed to solar radiation and its evaporative cooling effect. This again demonstrated that passive thermography can be employed by making full use of the weather and timing in façade inspection. Close up inspection will then be needed to ascertain the extent and cause of the cracks.

The infrared thermography had also picked up deteriorated brickworks at the Myanmar Railway Station Building in Yangon and defective render works at the Cathedral of Good Shepherd in Singapore (Tang, Krishnankutty and Wong 2013). At the former, deteriorated bricks will have different thermal heat capacity due to its porosity or water retention often giving rise of lower temperature profile as compared to sound bricks (Figure 13). At the Cathedral of Good Shepherd, from the thermograms captured on the façade after prolonged heating by solar radiation, the presence of 'cold spots' was linked to deteriorated render, but hot anomalies were subsequently found from breakout to be due later applied cement based render (Figure 14). This thus helped to identify locations of inappropriate cement render that had been applied onto historic brickworks 

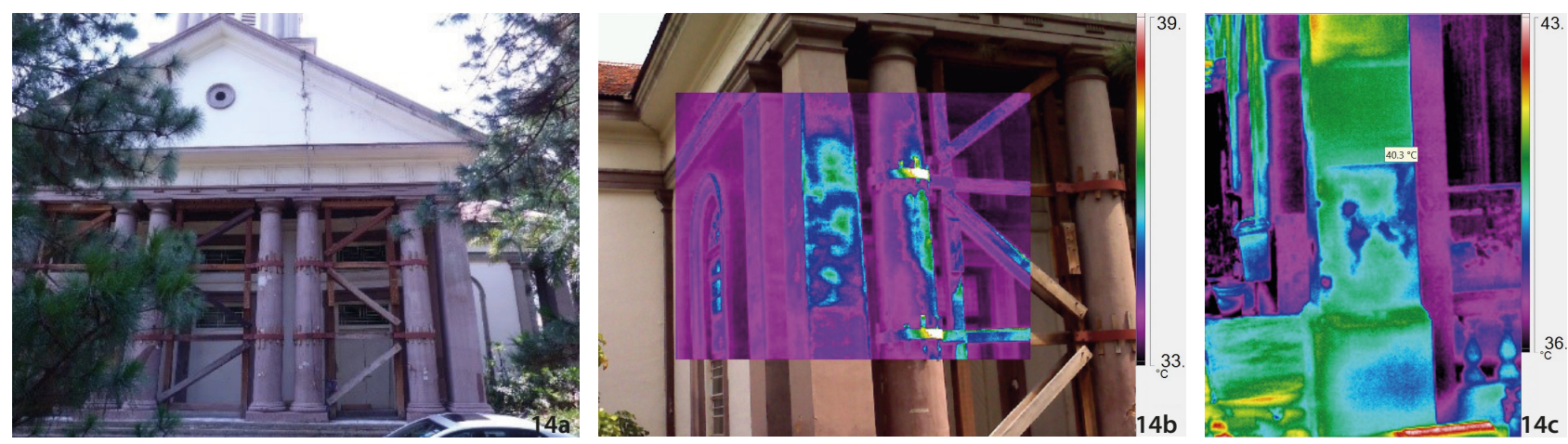

Figure 14 The left photo shows a section of the Cathedral of Good Shepherd. The centre and right photo show thermograms captured with thermal anomalies. The irregular cold spots are an indication of deteriorated and debonded render. A regular hotter area above the irregular cold spots in the right photo is due to the presence of latter applied cement-based render. This was applied apparently to address the deterioration of the historic render caused by the salt attack (Source: the author).
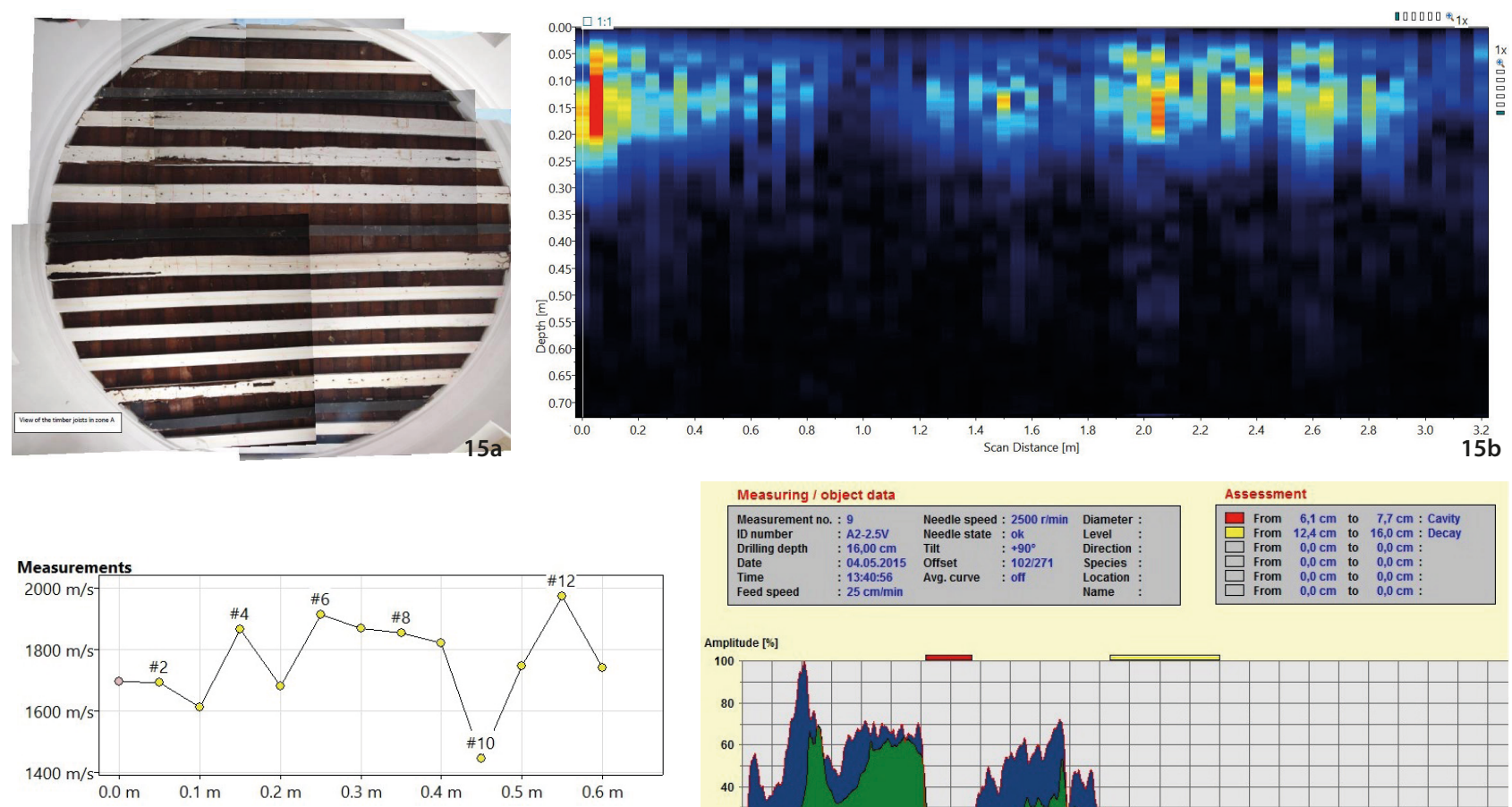

$15 c$
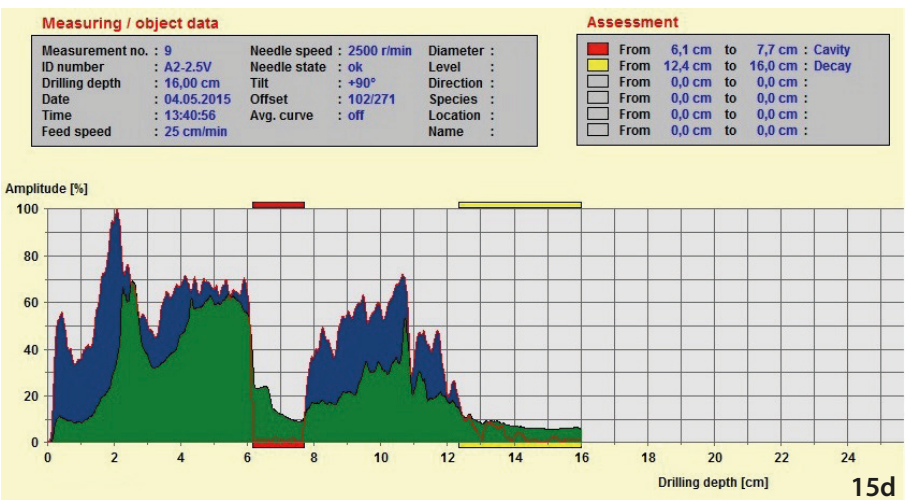

Figure 15 Top left photo shows the layout of the timber floor joists at the Caldwell House. The image at the top right shows a typical tomography of the pulse echo from a joist with cavity. The cavities appeared as reflected echoes. In the bottom left graph, variations in the ultrasonic pulse velocity are revealed with the localised cavity showing a much lower velocity. The size of the cavity was finally estimated with the timber resistograph is demonstrated in the bottom right graph (Source: the author).

which need to be removed as they are detrimental to the historical layers. The cement rich renders are too strong for the historical layers which can cause damages to the weaker render and substrate. In addition, such render can also be an additional source of soluble salt which can aggravate the deterioration of the traditional substrate.

During the restoration of the former Convent of Holy Infant Jesus Middle Education School (CHIJMES), extensive subterranean termite attack was uncovered on the timber floor joists at the Caldwell House, which was built in $1840-1841$. As it was not possible to remove the floor joists and floorboard for inspection, a combination of ultrasonic pulse echo tomography and ultrasonic pulse velocity measurement was used to scan every floor joist. In both methods, the frequency of the ultrasonic pulse used was $54 \mathrm{kHz}$. From the reflected ultrasonic signals, cavities in the timber caused by termite infestation were picked up. This was also verified by from the lower ultrasonic pulse velocity readings. The size of the cavity was then estimated from the timber resistograph carried out at the 

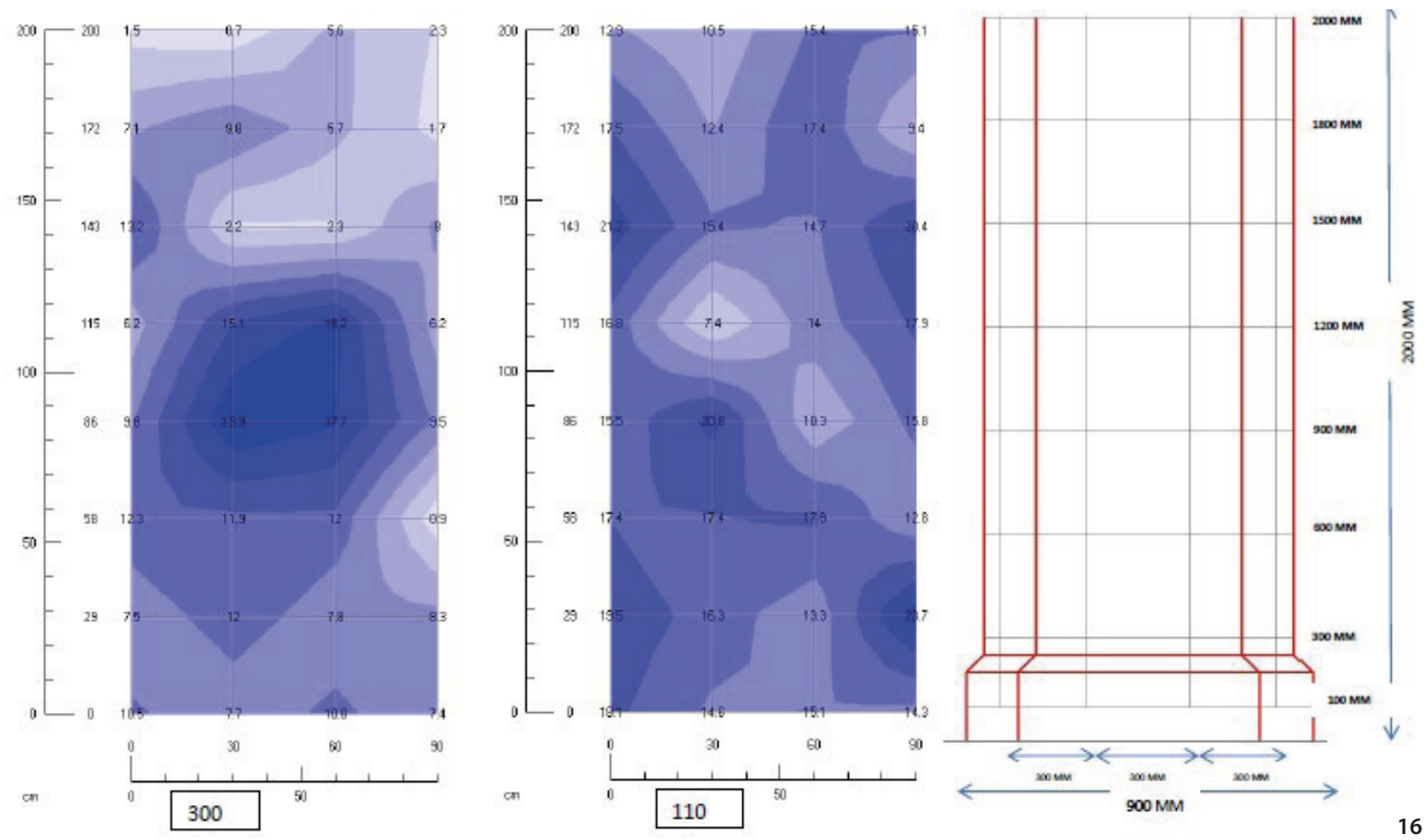

Figure 16 Microwave moisture tomograph on one of the columns showing moisture distribution at different depths. At about $300 \mathrm{~mm}$ depth, a concentrated zone of much higher relative moisture content was detected. The pattern of moisture distribution did not suggest any presence of uprising damp (Source: the author).

spots with cavities (Figure 15). This then allowed the true condition of the joists to be determined and appropriate repair methods designed for.

In the same project, rising damp and salt attack on the masonry columns were discerned and the rising damp treated via chemical injection. As with most interventions, post-treatment checks were carried out by gravimetric measurement of extracted powders. Powders of the bricks were extracted from different heights. However, in few of the columns, the brick powders showed persistently high moisture despite repeated chemical injections. This has resulted in multiple holes due to the repeated brick powders extracted, which was destructive and undesirable. The use of infrared thermography failed to identify the locations and cause of persistent dampness. Microwave moisture tomography was subsequently employed to better understand the cause and pattern of moisture distribution within these columns. The measurements were made with two different depth probes; namely 110 and $300 \mathrm{~mm}$ as the columns were about $500 \mathrm{~mm}$ thick. From the resulting tomograph, it was found that the rising treatment was effective. Instead, the high moisture was discovered to be concentrated in a localized zone about $1 \mathrm{~m}$ above the floor level and around the centre of the columns (Figure 16). Follow up targeted extraction of powder at this localised spot showed a high amount of hygroscopic salt and hygroscopic moisture content. Targeted salt treatment to the specific area was then carried out which eventually resolved the problem.

From the cases above, the infrared thermography proved to be an indispensable tool for scanning of the building façade given that the façade is exposed active heat flow from solar radiation. The depth from the surface which the thermography can detect any anomaly is dependent on the amount of heat flow and relative heat flow across the surface of different materials or subsurface features. It was shown to be very effective in fair-faced brick façade with different types of defects. As for plastered surfaces, it will be affected by the thickness of the plaster and depth of the sub-surface anomaly. As can be seen, moisture trapped within a wall cannot be successfully identified. In this regard, the microwave method was more effective but require close up access, unlike the thermography which can scan a wall from a distant.

For the case of timber, a combination of different techniques was found to be beneficial. Pulse echo and ultrasonic was used to delineate sections of the beams with large cavities. The resistograph was then followed through to quantify or estimate the size of damaged wood fibres. The pulse echo and ultrasonic methods could not 
determine the size of the cavity due to termite attack but are quick methods to screen through the timber to pinpoint locations with damages.

\section{Conclusion}

The various case studies herein demonstrated the indispensable advantages in the use of non-destructive tests as part of the restoration of heritage buildings, both as precondition assessment and as quality control tools during the intervention stage. The advent of improving computing power had allowed features to be visualised and data to be interpreted with greater ease. Still, meaningful interpretation of the signals would often require the skills and expertise of experienced engineers and specialists. To be truly effective, a combination of different methods is necessary, and one should not rely simply on one single method in any diagnosis (Wong and Dai 2003; Wong 2015). Verification through the destructive breakout, intrusive inspection or even sample extracted for laboratory analysis is in most instances inevitable and can improve the confidence and reliability of the non-destructive approaches. However, the use of non-destructive tests can minimise the extent of damages by optimising the extent and location of intrusive and destructive diagnosis.

\section{References}

Binda, Lugia, and Antonella Saisi. 2009. "Applications of NDTs to the Diagnosis of Historic Structures." Paper presented at NDTCE'09, Non-Destructive Testing in Civil Engineering, Nantes, June 30-July 3.

Concrete Society. 1997. Guidance on Radar Testing of Concrete Structures. Surrey: The Concrete Society.

Dackermann, Ulrike, Keith Crews, Bohumil Kasal, Jianchun Li, Mariapaola Riggio, Frank Rinn, and Thomas Tannert. 2014. "In-situ Assessment of Structural Timber Using Stress Wave Measurements." Materials and Structures 47 (5): 787-803.

Grinzato, Ermanno. 2012. "IR Thermography Applied to the Cultural Heritage Conservation." Paper presented at 18th World Conference on Nondestructive Testing, Durban, April 16-20.

Himi, Mahjoub, María de la Vega Pérez Gracia, Albert Casas, Josep Oriol Caselles Magallón, Jaime Clapes Boixader, and Lluis Rivero. 2016. "Non-destructive Geophysical Characterization of Cultural Heritage Buildings: Applications at Spanish Cathedrals." First Break 34 (8): 93-101.

Krause, Martin, Ulrike Dackermann, and Jianchun Li. 2015. "Elastic Wave Modes for the Assessment of Structural
Timber: Ultrasonic Echo for Building Elements and Guided Waves for Pole and Pile Structures.” Journal of Civil Structural Health Monitoring 5 (2): 221-249.

Maierhofer, C., K. Borchardt, and J. Henschen. 1995. "Application and Optimisation of Impulse-radar for Non-destructive Test in Civil Engineering." In Int. Symp. Non-Destructive Testing in Civil Engineering, edited by G. Schickert and H. Wiggenhauser, 663-672. Berlin: Deutsche Gesellschaft fur Zerstorungsfreie Prufung (DGZfP).

Maierhofer, Christiane, Astrid Ziebolz, and Christian Kopp. 2003. "ONSITEFORMASONRY_A European Research Project: On-site Investigation Techniques for the Structural Evaluation Historic Masonry." International Symposium on Non-destructive Testing in Civil Engineering.

McCann, D. M., and M. C. Forde. 2001 "Review of NDT Methods in the Assessment of Concrete and Masonry Structures." NDT \& E International 34 (2): 71-84.

Michaux, Christophe, and Michel Grill. 2011. "NDT 3D Tomographic Testing Cases on Concrete and National Heritage Buildings".

Plesu, Raluca, Gabriel Teodoriu, and George Taranu. 2012. "Infrared Thermography Applications for Building Investigation.” Buletinul Institutului Politehnic Din Iaşi LVIII (LXII): 157-168.

Ranalli, Danilo, Marco Scozzafava, and Marco Tallini. 2004. "Ground Penetrating Radar Investigations for the Restoration of Historic Buildings: Case study of the Collemaggio Basilica (L'Aquila, Italy)." Journal of Cultural Heritage 5 (1): 91-99.

Svahn, Helene. 2006. "Non-destructive Field Tests in Stone Conservation-Literature Study: Final Report for the Research and Development Project." Rapport från Riksantikvarieämbetet 4 .

Tang, H.S., P. Krishnankutty, and C.W. Wong. 2013. “Diagnostic Condition Assessment of a 180-year-old Church in Singapore for the Purpose of Restoration." Paper presented at International Conference on Sustainable Building Restoration and Revitalization, Shanghai, September 25-28.

Wong, Chung Wan, and Shibing Dai. 2003. "Restoration of Shanghai Plaster - An Example from the Singapore Ministry of Foreign Affairs Headquarter.” Paper presented at 2nd International Symposium on Building Pathology, Durability and Rehabilitation, Lisbon, November 6-8.

Wong, Chung Wan. 2015. "Investigation Techniques for Restoration of Heritage Buildings." Paper presented at ICOMOS-NMS World Heritage Day Symposium, Singapore, April 18. 